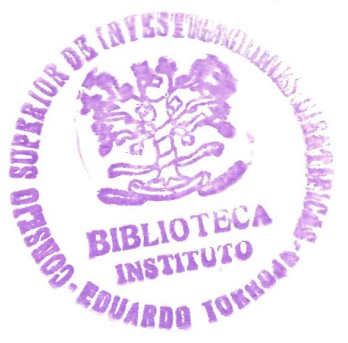

\title{
cubierta prefabricada
}

ISADORE THOMPSON, ingeniero

La cubierta de dos nuevos edificios, cuyo conjunto engloba la denominación San Mateo County, en California (EE. UU.), dedicado a fiestas y exposiciones mercantiles, está constituída por láminas en arco de medio punto, prefabricadas y de hormigón armado.

Estructuralmente ha sido proyectada por el autor, dejando la parte arquitectónica a Janssen, Daseking y Keller, arquitectos.

Cada uno de estos edificios tiene $61 \times 24,6 \mathrm{~m}$ en planta. Los elementos laminares, prefabricados, que componen la estructura de cubierta, tienen $30 \mathrm{~m}$ de longitud y $5,50 \mathrm{~m}$ de anchura, pesan 40 toneladas y se han prefabricado con hormigón ligero. Estos elementos salvan una luz de $24,6 \mathrm{~m}$, que es la anchura del edificio, y sobresalen formando voladizo $4,30 \mathrm{~m}$ hacia el interior donde forman patio los dos edificios $\mathrm{El}$ radio de estos elementos es de $3 \mathrm{~m}$ en su cuerpo y se aumenta a $4,60 \mathrm{~m}$ en la parte en voladizo, logrando asi dar un aspecto de marquesina plana.

El proyecto presenta su interés desde el punto de vista arquitectónico. Los factores económicos han sido la razón dominante para el empleo de estos elementos prefabricados.

Los edificios se han separado unos $52 \mathrm{~m}$, unidos por medio de una arcada que alberga en su interior los servicios de cocina e higiénicos. Este tramo de unión está formado por dos filas de soportes y vigas, que constituyen su parte anterior y posterior. Para soportar la cubierta en esta parte, entre estas dos filas se han colocado elementos estructurales más ligeros.

Los elementos laminares en arco se han espaciado a $5,5 \mathrm{~m}$, y se han proyectado para apoyarse en cuatro puntos, que corresponden a otros tantos soportes. Tanto los muros como los soportes se prefabricaron delante del edificio. Los soportes posteriores se hormigonaron "in situ", dándoles mayor sección para poder resistir a los esfuerzos laterales.

Los elementos celulares se anclaron a los soportes por medio de barras tubulares. Con objeto de ganar rigidez, se aumentó el espesor en los bordes, guardando un espesor general en el resto de $9 \mathrm{~cm}$. Este espesor también se reforzó en los puntos de apoyo.

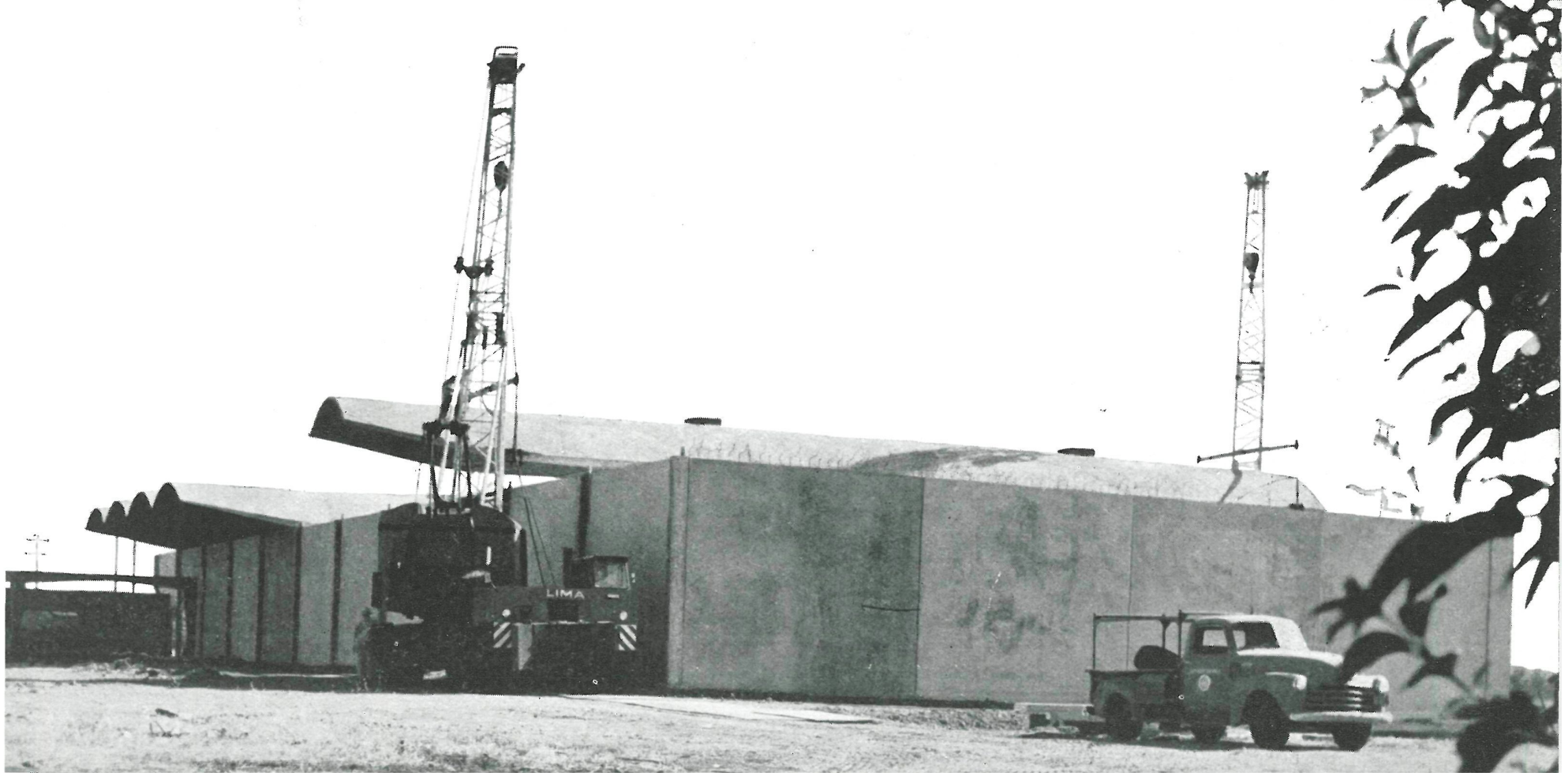



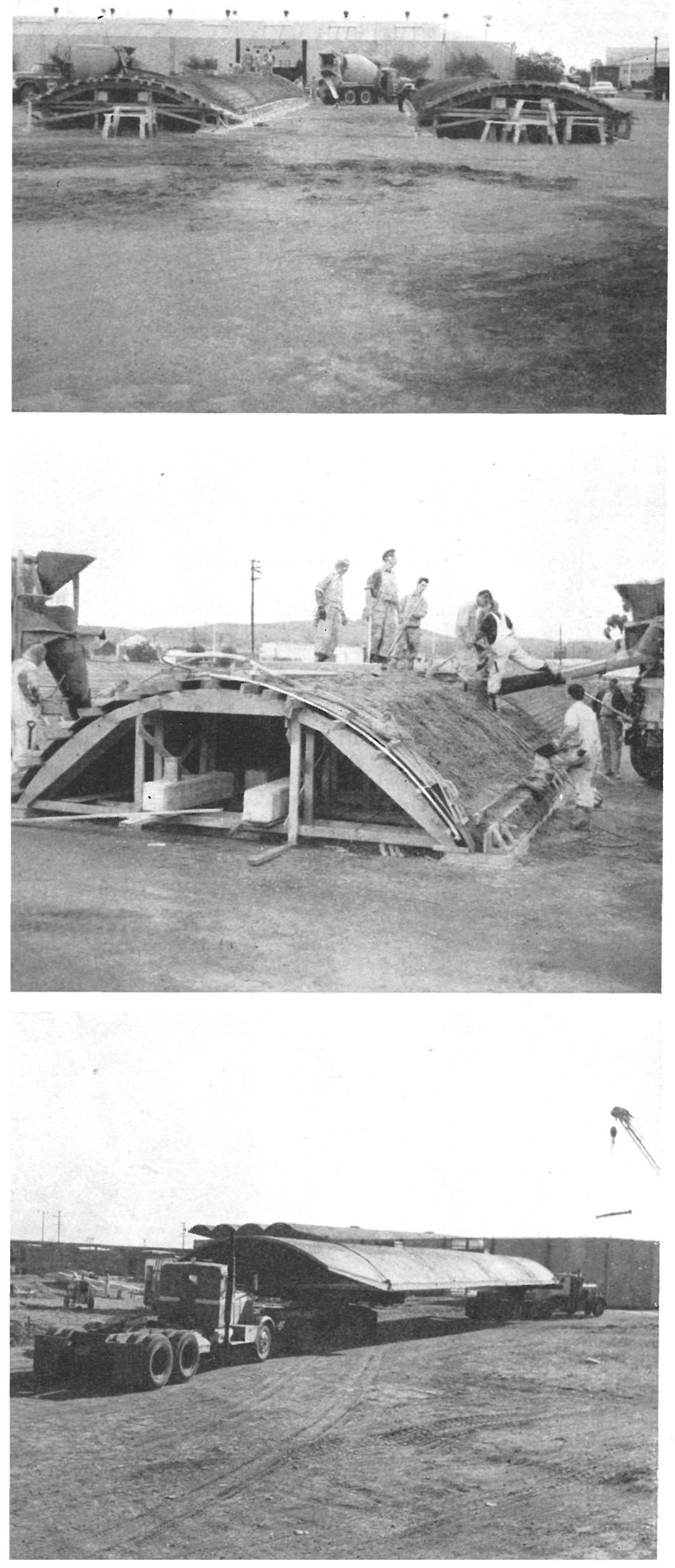

Encofrados empleados en la prefabricación de elementos. Hormigonado de un elemento.

Elemento laminar, en arco de medio punto, utilizado para la cubierta.

Las láminas en arco se armaron con barras número 4, transversales, en la parte superior, y número 2 en la inferior. Las armaduras longitudinales forman una simple capa de barras espaciadas a $23 \mathrm{~cm}$, y otras, espaciadas a $9 \mathrm{~cm}$. Con objeto de evitar los esfuerzos cortantes se han previsto armaduras transversales en las proximidades de los soportes y en los arranques a partir de los mismos.

Para aprovechar el hueco que dejan estos elementos en arco se cubrió con cristaleras provistas de cercos de aluminio, con lo que se mejorará la iluminación natural. Estos cercos no tienen carga alguna, y, como consecuencia, no ejercen interferencia alguna de tipo estructural.

Entre cada dos elementos laminares en arco se ha dejado una junta de $25 \mathrm{~mm}$ de luz, que se ha cerrado con un canalón metálico que, posteriormente se ha recubierto con material de cubrición.

Antes de proceder a la preparación de encofrados para el hormigonado de los elementos laminares en arco, se procedió a un estudio previo del número de reempleos, maniobras y grúas a que éstas daban lugar, lo que permitió llegar a una solución óptima. Los encofrados se componen de una serie de cerchas de madera, sobre las que se colocaron listones de $5 \times 10 \mathrm{~cm}$ de escuadría, y sobre éstos se fijaron planchas de madera contrachapada. Las cerchas se espaciaron a 1,20 metros.

Era de gran importancia en el proyecto de los encofrados que éstos no se moviesen durante las operaciones de desencofrado y al levantar los elementos con las grúas. A lo largo de cada borde del encofrado se hormigonó una banda de cimiento o encofrado se hormigonó una banda de cimiento o dera, de $5 \mathrm{~cm}$ de lado, y sobre esta pieza se clavaron las extremidades de las placas de madera contrachapada. Por debajo del encofrado se colocaron contrapesos de hormigón.

Antes de desencofrar, los elementos se dejaron siete días para el proceso de curado. La preparación del encofrado para proceder a un nuevo hormigonado necesitó un período de cuatro días, consiguiendo así ciclos de catorce días para cada elemento. La resistencia prevista para el hormigón ha sido de $263 \mathrm{~kg} / \mathrm{cm}^{2}$ a los veintiocho días.

La relación agua-cemento fue muy controlada, ya que si el hormigón era muy seco carecía de suficiente docilidad para sacarle de la cuba que lo ciente docilidad para sacarle de la cuba que lo húmedo resultaba excesivamente dócil para mantenerlo en los encofrados.

La elevación de estos elementos a partir de los encofrados y su transporte y colocación en su lugar definitivo constituía una serie de operaciones de gran importancia y riesgo. Estas maniobras necesitaron de dos grúas móviles. Con objeto de evitar deformaciones en el curso de estas operaciones se colocaron tirantes de arriostramiento, con carácter provisional, en los elementos.

Durante el transporte, una extremidad del elemento se situó en un remolque, que llevaba colocada ex profeso una pieza que podía girar en un plano horizontal, y la otra extremidad se mantenía suspendida de la grúa móvil. Los elementos se almacenaron a pie de obra, de donde se volvían a macenaron a pie de obra, de donde se volvían a
transportar y colocar en posición definitiva siguiendo maniobras muy similares a las empleadas para sacar los elementos de los encofrados y su transporte al lugar de almacenamiento, es decir, siempre utilizando dos grúas móviles. 